\title{
Design Optimization of Composite Lay-up Sequence and Orientation to Achieve Minimum Weight for Racing Seat
}

\author{
Pranali Yogesh Kajale
}

\begin{abstract}
Composites have proved their usefulness in the automotive industry during recent years. Many automobile companies use them in different parts to reduce weight without hampering strength. In a composite material, Lay-up sequence and orientation highly affects the properties of the laminate. Therefore, it is important to perform design optimization on a component to achieve high strength in minimum weight. This paper deals with the optimization of lay-up for composite Racing Seat using finite element analysis. Different lay-up sequences for laminates including, cross-ply [0/90]n, angle-ply $[ \pm \alpha]_{n}$, and $[0 / 90 / \pm \alpha]_{n}$ are analysed. The lay-up sequence, orientation and ply number are optimized using composite material carbon fibre/Epoxy. Driver's ergonomics and impact sustainability are considered constraints for weight optimization. Driver's ergonomics were based on 95th percentile male and 5th percentile female rule. Force analysis is performed on the seat according to SFI 39.2 to evaluate the strength requirement. Finite element analysis of composite racing seat is performed via commercial finite element code ANSYS and using the capabilities of ANSYS Composite PrepPost (ACP) to form desired composite lay-up. A finite element code is based on classical lamination theory; including Puck's failure criterion for first-ply failure. The seat is divided into three portions with a different number of layers considering the values and specific nature of acting forces; which resulted in different thicknesses in different regions. The optimization results show that for all the angles of Angle-ply laminate considered, Angle-ply laminates with an angle of $45^{\circ}$ provides a more optimum design. The minimum weight obtained is $10.15 \mathrm{~kg}$.
\end{abstract}

Keywords: Composite Racing Seat, Weight Optimization, FEA, Cross-ply, Angle-ply, Puck's failure criteria.

\section{INTRODUCTION}

'Light-weight' is the prime requirement of any racing car as it directly affects the speed of the vehicle. The structural components of any car require adequate strength with minimal weight while meeting the loading requirements including impacts. As such, three parameters viz. (a) material selection, (b) geometry and (c) quality of construction play a vital role in achieving high strength to weight ratio[1]. As regards materials, fibre reinforced composite materials are being widely used in automotive industries due to their

Manuscript received on September 10, 2021.

Revised Manuscript received on September 17, 2021.

Manuscript published on September 30, 2021.

* Correspondence Author

Pranali Yogesh Kajale*, Department of Mechanical Engineering, Sinhgad College of Engineering, Pune (Maharashtra), India. Email: Kajalepranali@gmail.com

(C) The Authors. Published by Blue Eyes Intelligence Engineering and Sciences Publication (BEIESP). This is an open access article under the CC BY-NC-ND license (http://creativecommons.org/licenses/by-nc-nd/4.0/) advantages like high strength to weight ratio, high specific stiffness and customizable material properties. However, unlike metallic materials, composites have an anisotropic nature i.e., their properties vary depending on load direction and fibre orientation. Even a slight change in thickness of a layer, orientation of fibre or stacking sequence results in different behaviour of the same material structure. Hence, it is difficult to design an optimal composite structure as its performance is highly dependent. Many researchers have tried different approaches to obtain an optimal design having minimal weight with the required strength. Shrivastava et al.[2], presented an optimal design for composite wing-panel applying genetic algorithm (GA) and finite element method (FEM). Blasques and Stolpe [3], identified optimal fibre orientations and laminate thicknesses in maximum stiffness and minimum weight design of laminated composite beams. Mian et al.[4], performed the weight optimization of composite pressure vessel design, using both Tsai-Wu failure and the maximum stress criteria for the first-ply failure. Liu et al.[5], examined a lamination parameter-based method for seeking the best stacking sequence of laminated composite wing structures with blending and mechanical performance requirements. Chandak et al.[6], have studied the effect of material and orientation on strength of side door intrusion beam numerically. Sathaye and Bhattacharyya[7], have demonstrated the multi-step optimization approach used in the design and development of car hood. In any racing car, 'Racing Seat' is a critical component since any damages to it can directly harm the driver apart from affecting the driver's comfort. It needs to be designed optimally so that it can sustain the external impacts while offering needed comfort to the driver. The geometry of the racing seat has to offer seating comfort to any driver while racing and operating all functions of the vehicle. Many researchers have studied the high-speed impact analysis and improved the seat structure to minimise the risk of injury[8,9] The main objective of this paper is to analyse and arrive at the optimal design for a Racing seat using composite material which can be constructed with minimum weight to sustain intended impact loads thereby offering protection and comfort to the driver. The minimum dimensions and geometry are decided in the CAD model. SFI 39.2 standards[10] are considered for impact analysis of the seat. The optimization process is performed using commercial finite element code ANSYS where parameters like the lay-up sequence, orientation and ply number have been considered while designing the plies.

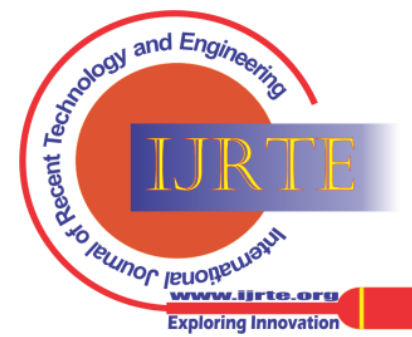




\section{Design Optimization of Composite Lay-up Sequence and Orientation to Achieve Minimum Weight for Racing Seat}

Different lay-up sequences for laminates including, cross-ply $[0 / 90]_{\mathrm{n}}$, angle-ply $[ \pm \alpha]_{\mathrm{n}}$, and $[0 / 90 / \pm \alpha]_{\mathrm{n}}$ are analysed. The first-ply failure approach is checked using the Puck's failure criteria.

\section{CLASSICAL LAMINATE THEORY}

The classical laminate theory is used for analysing the mechanical behaviour of laminate. The classical theory of laminates uses the first-order scheme for the strains in which the strain field is expressed as[11,12]:

$$
\begin{aligned}
& \varepsilon(M)=\varepsilon_{\mathrm{m}}(\mathrm{M})+\varepsilon_{f}(M) \\
& {\left[\begin{array}{c}
\varepsilon_{x x} \\
\varepsilon_{y y} \\
\gamma_{x y}
\end{array}\right]=\left[\begin{array}{c}
\varepsilon_{x x}^{0} \\
\varepsilon_{y y}^{0} \\
\gamma_{x y}^{0}
\end{array}\right]+z\left[\begin{array}{c}
k_{x} \\
k_{y} \\
k_{x y}
\end{array}\right]} \\
& \varepsilon_{x x}^{0}=\frac{\partial u_{0}}{\partial x}(x, y),
\end{aligned}
$$

$$
\begin{array}{ll}
\varepsilon_{y y}^{0}=\frac{\partial u_{0}}{\partial y}(x, y), & \gamma_{x y}^{0}=\frac{\partial u_{0}}{\partial y}+\frac{\partial v_{0}}{\partial x} \\
k_{x}=-\frac{\partial^{2} w_{0}}{\partial x^{2}}(x, y), & k_{y}=-\frac{\partial^{2} w_{0}}{\partial y^{2}}(x, y)
\end{array}
$$

and

$$
k_{x y}=-2 \frac{\partial^{2} w_{0}}{\partial x \partial y}(x, y)
$$

$\varepsilon_{\mathrm{m}}(\mathrm{M})$ and $\varepsilon_{f}(M)$ represents in-plain strains and flexural strains respectively.

The stress field for the layer $k$ can be represented as[13]:

$$
\begin{array}{r}
{\left[\begin{array}{c}
\sigma_{x x} \\
\sigma_{y y} \\
\sigma_{x y}
\end{array}\right]=\left[\begin{array}{lll}
Q_{11}^{\prime} & Q_{12}^{\prime} & Q_{16}^{\prime} \\
Q_{12}^{\prime} & Q_{22}^{\prime} & Q_{26}^{\prime} \\
Q_{16}^{\prime} & Q_{26}^{\prime} & Q_{66}^{\prime}
\end{array}\right]\left[\begin{array}{c}
\varepsilon_{x x}^{0} \\
\varepsilon_{y y}^{0} \\
\gamma_{x y}^{0}
\end{array}\right]} \\
+z\left[\begin{array}{lll}
Q_{11}^{\prime} & Q_{12}^{\prime} & Q_{16}^{\prime} \\
Q_{12}^{\prime} & Q_{22}^{\prime} & Q_{26}^{\prime} \\
Q_{16}^{\prime} & Q_{26}^{\prime} & Q_{66}^{\prime}
\end{array}\right]\left[\begin{array}{c}
k_{x} \\
k_{y} \\
k_{x y}
\end{array}\right]
\end{array}
$$

Where $Q_{i j}^{\prime}$ are called the elements of the transformed reduced stiffness matrix $\left[Q^{\prime}\right]$ and are given by[14]:

$$
\begin{aligned}
& Q_{11}^{\prime}=Q_{11} c^{4}+2\left(Q_{12}+2 Q_{66}\right) s^{2} c^{2}+Q_{22} s^{4} \\
& Q_{12}^{\prime}=\left(Q_{11}+Q_{22}-4 Q_{66}\right) s^{2} c^{2}+Q_{12}\left(s^{4}+c^{4}\right) \\
& Q_{16}^{\prime}=\left(Q_{11}-Q_{12}-2 Q_{66}\right) s c^{3}+\left(Q_{12}-Q_{22}+2 Q_{66}\right) s^{3} c \\
& Q_{22}^{\prime}=Q_{11} s^{4}+2\left(Q_{12}+2 Q_{66}\right) s^{2} c^{2}+Q_{22} c^{4} \\
& Q_{26}^{\prime}=\left(Q_{11}-Q_{12}-2 Q_{66}\right) s^{3} c+\left(Q_{12}-Q_{22}+2 Q_{66}\right) s c^{3} \\
& Q_{66}^{\prime}=\left(Q_{11}+2\left(Q_{12}+2 Q_{66}\right)+Q_{22}\right) s^{2} c^{2}+Q_{66}\left(s^{4}+c^{4}\right)
\end{aligned}
$$

Where $\mathrm{c}=\cos \theta, \mathrm{s}=\sin \theta$ and $\mathrm{Q}_{\mathrm{ij}}$ are the reduced stiffness for each lamina and depends on elastic properties of the material along the principal directions:

$$
\begin{gathered}
Q_{11}=\frac{E_{L}}{1-\gamma_{L T} \gamma_{T L}}, Q_{12}=\frac{\gamma_{L T} E_{T}}{1-\gamma_{L T} \gamma_{T L}} \\
Q_{22}=\frac{E_{T}}{1-\gamma_{L T} \gamma_{T L}}, \quad Q_{66}=G_{L T}
\end{gathered}
$$

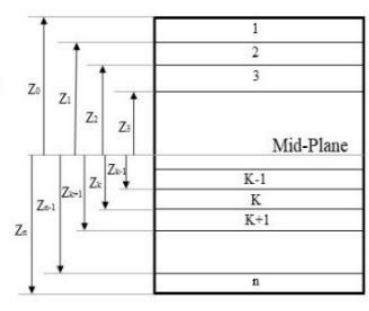

Figure 1 Laminated composite shell and coordinate locations of plies in a laminate

The resultant forces and moments per unit length applied at middle of the surface of each laminate can be obtained as:

$$
\begin{aligned}
& \left\{\begin{array}{c}
N_{x} \\
N_{y} \\
N_{x y}
\end{array}\right\}=\int_{-h / 2}^{h / 2}\left\{\begin{array}{l}
\sigma_{x x} \\
\sigma_{y y} \\
\sigma_{x y}
\end{array}\right\} d z=\sum_{k=1}^{n} \int_{Z_{k-1}}^{Z_{k}}\left\{\begin{array}{l}
\sigma_{x x} \\
\sigma_{y y} \\
\sigma_{x y}
\end{array}\right\} d z \\
& \left\{\begin{array}{c}
M_{x} \\
M_{y} \\
M_{x y}
\end{array}\right\}=\int_{-h / 2}^{h / 2}\left\{\begin{array}{l}
\sigma_{x x} \\
\sigma_{y y} \\
\sigma_{x y}
\end{array}\right\} Z d z=\sum_{k=1}^{n} \int_{Z_{k-1}}^{Z_{k}}\left\{\begin{array}{l}
\sigma_{x x} \\
\sigma_{y y} \\
\sigma_{x y}
\end{array}\right\} Z d z
\end{aligned}
$$

Where, $\mathrm{h}=$ total thickness and $\left(\mathrm{Z}_{\mathrm{k}}, \mathrm{Z}_{\mathrm{k}-1}, \mathrm{k}=1,2, \ldots \mathrm{n}\right)$ are the coordinates of the $\mathrm{k}^{\text {th }}$ lamina boundaries measured from the middle surface (see Figure 1).

Based on the above equations, the stress-strain relation is $\left.\begin{array}{l}\text { given as: } \\ N_{x} \\ N_{y} \\ N_{x y} \\ M_{x} \\ M_{Y} \\ M_{x y}\end{array}\right]=\left[\begin{array}{llllll}A_{11} & A_{12} & A_{16} & B_{11} & B_{12} & B_{16} \\ A_{12} & A_{22} & A_{26} & B_{12} & B_{22} & B_{26} \\ A_{16} & A_{26} & A_{66} & B_{16} & B_{26} & B_{66} \\ B_{11} & B_{12} & B_{16} & D_{11} & D_{12} & D_{16} \\ B_{12} & B_{22} & B_{26} & D_{12} & D_{22} & D_{26} \\ B_{16} & B_{26} & B_{66} & D_{16} & D_{26} & D_{66}\end{array}\right]\left[\begin{array}{c}\varepsilon_{x x}^{0} \\ \varepsilon_{y y}^{0} \\ \gamma_{x y}^{0} \\ k_{x} \\ k_{y} \\ k_{x y}\end{array}\right]$

The constitutive equation can be also expressed in a condensed form as follows:

$$
\left[\begin{array}{l}
N \\
M
\end{array}\right]=\left[\begin{array}{ll}
A & B \\
B & D
\end{array}\right]\left[\begin{array}{c}
\varepsilon_{m} \\
k
\end{array}\right]
$$

Where [A], [B] and [D] are in-plane stiffness matrix, coupling matrix and flexural stiffness matrix. The values of $\mathrm{A}_{\mathrm{ij}}, \mathrm{B}_{\mathrm{ij}}, \mathrm{D}_{\mathrm{ij}}$ are given as:

$$
\begin{aligned}
A_{i j} & =\sum_{k=1}^{n}\left(Q_{i j}^{\prime}\right)_{k}\left(z_{k}-z_{k-1}\right), \\
B_{i j} & =\sum_{k=1}^{n}\left(Q_{i j}^{\prime}\right)_{k}\left(z_{k}^{2}-z_{k-1}^{2}\right), \\
D_{i j} & =\sum_{k=1}^{n}\left(Q_{i j}^{\prime}\right)_{k}\left(z_{k}^{3}-z_{k-1}^{3}\right)
\end{aligned}
$$

The principal stresses and strains components for layer $\mathrm{k}$ can be obtained based on the following[14]:

$$
\begin{array}{r}
{\left[\begin{array}{l}
\sigma_{11} \\
\sigma_{22} \\
\tau_{12}
\end{array}\right]=\left[\begin{array}{ccc}
c^{2} & s^{2} & 2 s c \\
s^{2} & c^{2} & -2 s c \\
-c s & c s & c^{2}-s^{2}
\end{array}\right]\left[\begin{array}{l}
\sigma_{x x} \\
\sigma_{y y} \\
\sigma_{x y}
\end{array}\right]\left[\begin{array}{l}
\varepsilon_{11} \\
\varepsilon_{22} \\
\varepsilon_{12}
\end{array}\right]} \\
=\left[\begin{array}{ccc}
c^{2} & s^{2} & s c \\
s^{2} & c^{2} & -s c \\
-2 c s & 2 c s & c^{2}-s^{2}
\end{array}\right]\left[\begin{array}{l}
\varepsilon_{x x} \\
\varepsilon_{y y} \\
\varepsilon_{x y}
\end{array}\right]
\end{array}
$$

The optimum and efficient design can only be produced by considering the strength requirement in different areas of any component. 
A common approach towards it is to apply a failure criterion to it. In the present paper, Puck's failure criteria[15,16] is used as it allows for a distinction between initial and final failure. The failures are categorized into two types viz. Fibre Failure (FF) and Inter-Fibre Failure (IIF). The FF type is further categorized into tension and compression modes, whereas depending upon the ratio of transverse $\left(\sigma_{2}\right)$ to shear $\left(\sigma_{12}\right.$ or $\left.\sigma_{21}\right)$ stress, the IFF type is categorized into three modes A, B, and C.

The maximum failure conditions for Fibre Failure (FF) is given by,

$$
\begin{aligned}
& \text { FF Tension: } \frac{1}{\varepsilon_{1 t}}\left(\varepsilon_{1}+\frac{\gamma_{f 12}}{E_{f 1}} m_{\sigma f} \sigma_{2}\right)=1 \\
& \text { FF Compression: } \frac{1}{\varepsilon_{1 c}}\left(\varepsilon_{1}+\frac{\gamma_{f 12}}{E_{f 1}} m_{\sigma f} \sigma_{2}\right) \\
& =1-\left(10 \gamma_{21}\right)^{2}
\end{aligned}
$$

Maximum failure conditions for Inter-Fibre Failure (IIF) is given by,

$$
\begin{gathered}
\text { Mode } A: \sqrt{\left(\frac{\sigma_{12}}{S_{21}}\right)^{2}+\left(1-p_{\perp \|}^{(+)} \frac{S_{2 T}}{S_{21}}\right)^{2}\left(\frac{\sigma_{2}}{S_{2 T}}\right)^{2}} \\
+p_{\perp \|}^{(+)} \frac{\sigma_{2}}{S_{21}}=1-\left|\frac{\sigma_{1}}{\sigma_{1 D}}\right| \\
\text { Mode } B: \frac{1}{S_{21}}\left(\sqrt{\sigma_{21}^{2}+\left(p_{\perp \|}^{(-)} \sigma_{2}\right)^{2}}+p_{\perp \|}^{(-)} \sigma_{2}\right) \\
=1-\left|\frac{\sigma_{1}}{\sigma_{1 D}}\right| \\
\text { Mode } \left.C:\left[\frac{\sigma_{21}}{2\left(1+p_{\perp \perp}^{(-)} S_{21}\right)}\right)^{2}+\left(\frac{\sigma_{2}}{S_{2 C}}\right)^{2}\right] \frac{S_{2 C}}{-\sigma_{2}} \\
=1-\left|\frac{\sigma_{1}}{\sigma_{1 D}}\right|
\end{gathered}
$$

Where $\varepsilon_{1 t}$ and $\varepsilon_{1 c}$ are ultimate strain in tension and compression, respectively, and $\varepsilon_{1}$ is the current strain. $\gamma_{12}$ is a shear strain, which is assumed to be equal to zero on tests of unidirectional laminates. The parameter $v_{\mathrm{f} 12}$ is the Poisson's ratio for fibres, and $m_{\sigma \mathrm{f}}$ is a mean stress magnification factor for fibres in the transverse direction and is assumed to be equal to 1 for the tests of unidirectional laminates. The parameter $p_{\perp \|}^{(-)}$is the slope of the $\left(\sigma_{1}, \sigma_{12}\right)$ failure curve when $\sigma_{1}<=0, p_{\perp \|}^{(+)}$is the slope of the $\left(\sigma_{1}, \sigma_{12}\right)$ failure curve when $\sigma 1>0$, and $p_{\perp \perp}^{(-)}$is the slope of the $\left(\sigma_{1}, \sigma_{21}\right)$ failure curve when $\sigma_{1}<=0$. The parameter $\sigma_{1 \mathrm{D}}$ is a stress value for linear degradation[17].

The failure condition equations are modified such that the left side of the equations is equal to 1 which further implies that the failure occurs when the modified equation value, also called inverse reverse factor (IRF), exceeds 1.

\section{FINITE ELEMENT MODEL SIMULATION AND FORCE DISTRIBUTION}

\section{A. CAD Model}

The Racing seat shall consider the driver's ergonomics and comfort while deciding the minimum dimensions. From 5th percentile female to 95th percentile male body dimensions are considered while designing the seat. The lay-back angle is set to nearly $18^{\circ}$ to offer a comfortable position while driving. Suitable cut-outs for the passing of harness are provided at appropriate locations as per formula SAE rules[18].

Figure 3 Meshed model of racing seat

The Finite element model of the racing seat is developed in the ANSYS 2020R2 software ACP module considering it as a shell body with an element size of $15 \mathrm{~mm}$, involving 2,673 nodes and 11,086 elements. SOLID186 layered elements are developed because of their higher-order 3-D 20-node quadratic displacement behaviour. Material coordinate systems, called rosettes are created for defining material directions for composite lay-up. The thickness is applied from nodal coordinates which guide modelling ply groups to form desired composite lay-up as shown in Figure 3.

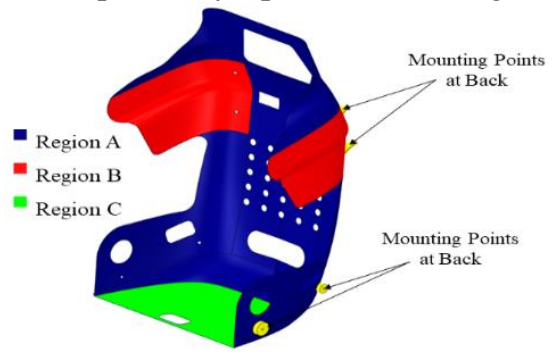

Figure 4 Racing seat divided in regions and it's mounting points 


\section{Design Optimization of Composite Lay-up Sequence and Orientation to Achieve Minimum Weight for Racing Seat}

Further, the analysis is performed in ANSYS Static structural module. As mentioned earlier, loads at three positions i.e., Head, shoulder and Pelvis are applied one by one. In every case, the racing seat is fixed at eight mounting points. (See Figure 4) Total deformation, Principal stresses and Inverse reverse factor(IRF) are monitored as output parameters.

\section{Statement of Optimization}

The optimal design problem of the racing seat is to attain minimum weight under constraints of both, minimal required dimensions and impact sustainability, according to design constraints. The Weight of a component mainly depends on the size and the loading conditions acting on it. In the case of the racing seat, the minimum size is selected based on the most important criteria, Driver's ergonomics. Driver's ergonomics concerns with the understanding of the interaction among the driver and other components of the vehicle. Thus, the minimum size is selected to improve the overall performance of the vehicle and comfort the driver.

The second constraint for weight is the impact sustainability. The impact sustainability of the racing seat is checked according to the guidelines mentioned in SFI 39.2. According to the guidelines, any racing seat should protect the driver from external impacts. Hence, the design of the racing seat is extended from the sides. Furthermore, the deformations produced due to impacts are restricted to $12.5 \mathrm{~mm}$ (a half-inch) to reduce the risk of injury possible due to deformation. The optimization model of the design includes the design variables, objective function and design constraints.

Design variables: The number of layers and orientation angle of the Carbon fibre/Epoxy layer are considered for the optimal design problem. The material properties of Carbon fibre/Epoxy are listed in Table- II.

Table- II: Measured engineering constants and typical strength of unidirectional carbon fibre/epoxy composite

\begin{tabular}{|l|l|}
\hline Strength properties & Value \\
\hline Density & $1540 \mathrm{~kg} / \mathrm{m}^{3}$ \\
\hline Young's modulus in X direction & $209 \mathrm{GPa}$ \\
\hline Young's modulus in Y and Z direction & $9.45 \mathrm{GPa}$ \\
\hline Poisson's ratio in XY and XZ & 0.27 \\
\hline Poisson's ratio in YZ & 0.4 \\
\hline Shear modulus in XY and XZ & $5500 \mathrm{MPa}$ \\
\hline Shear modulus in YZ & $3900 \mathrm{MPa}$ \\
\hline Tensile strength in X direction & $1979 \mathrm{MPa}$ \\
\hline Tensile strength in Y and Z direction & $26 \mathrm{MPa}$ \\
\hline Compressive strength in X direction & $893 \mathrm{MPa}$ \\
\hline Compressive strength in Y and Z direction & $139 \mathrm{MPa}$ \\
\hline Shear strength in XY and XZ & $100 \mathrm{MPa}$ \\
\hline Shear strength in YZ & $50 \mathrm{MPa}$ \\
\hline
\end{tabular}

Objective function: The objective of the paper is to produce an optimal design for a Racing seat using composite material which can be constructed with minimum weight to sustain intended impact loads thereby offering protection and comfort to the driver.

The intensity of force is not the same throughout the surface of the seat. Therefore, the Seat is divided into three portions with a different number of layers considering the values and specific nature of acting forces; which resulted in different thicknesses in different regions, see Figure 4.

\section{RESULT AND DISCUSSION}

A. Cross-ply [0/90 $]_{n}$ Composite Laminate:

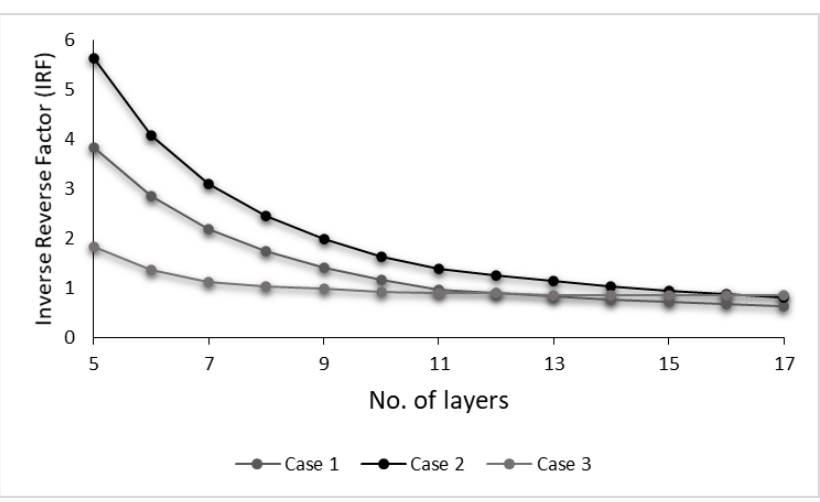

Figure 5 Graphical representation of Inverse Reverse Factor(IRF) as function of number of layers in cross-ply laminate

Initially, the number of layers (n) is set to 5 in all three regions of the seat. Then, the number of layers is increased in the critical portions where the stress value is high. The limiting condition is set where the IRF value is less than 1 . When the number of plies at Region $\mathrm{A}$ is reached at 11 , failure in that region is not observed for all three cases of force and hence it was concluded that a further increase of plies is not required. The same approached was followed for Region B and C. Following this, the converged solution is obtained when region A has 11 layers, region B has 17 layers and region $C$ has 5 layers of [0/90] cross-ply laminate. The weight achieved at the converged solution is $13.27 \mathrm{~kg}$. Also, maximum stress and deformation are $423.26 \mathrm{MPa}$ and 4.95 $\mathrm{mm}$ respectively. Figure 5 shows the graph of inverse reverse factor (IRF) as a function of the number of plies.

\section{B. Angle-ply $[ \pm \theta]$ n Composite Laminate:}

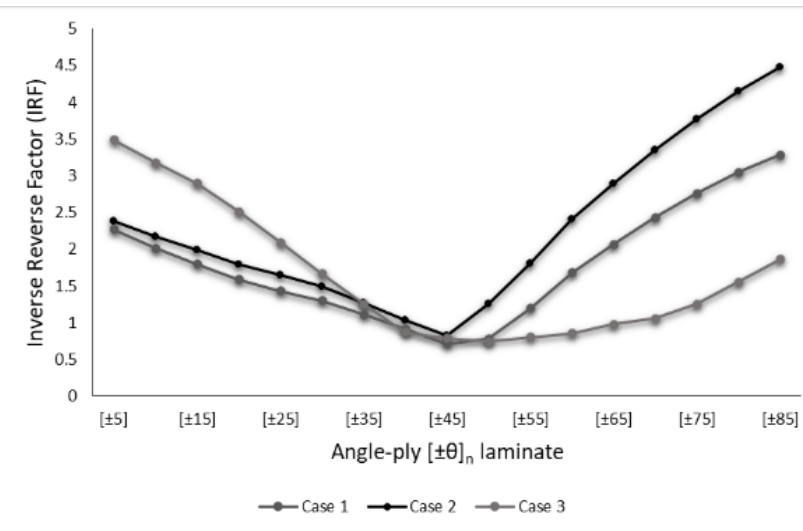

Figure 6 Graphical representation of Inverse Reverse Factors (IRF) for different angles in angle-ply $[ \pm \boldsymbol{\theta}] \mathbf{n}$ laminate

In this case, the number of layers (n) is set to 10,16 and 4 for regions $\mathrm{A}, \mathrm{B}$ and $\mathrm{C}$ respectively. At every interval of $5^{\circ}$, IRF was monitored starting from $\left[ \pm 5^{\circ}\right]_{\mathrm{n}}$ angle ply laminate. It is seen from the graph (see Figure 6) that the best suitable value for $\theta$ is $45^{\circ}$ as IRF is minimum and less than 1 . The maximum stress and deformation observed for this condition are 320.25 $\mathrm{MPa}$ and $8.32 \mathrm{~mm}$ respectively.

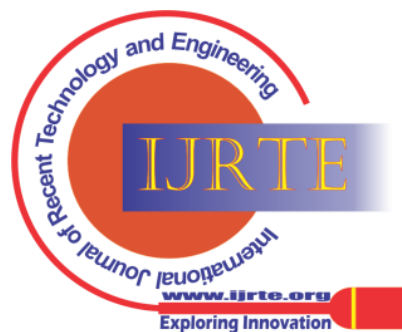


Even though the maximum deformation observed for angle ply laminate is more than the cross-ply laminate, it is under the permissible limit of a half-inch and hence acceptable. Furthermore, the number of layers at regions A, B and C are varied as listed in Table- III. It can be observed that 9,15 and
3 layers at regions $\mathrm{A}, \mathrm{B}$ and $\mathrm{C}$ respectively provide the best possible results in terms of IRF, stress and deformation. Finally, the weight of the seat using angle ply laminate is obtained as $10.939 \mathrm{~kg}$.

\section{Angle-ply $[0 / 90 / \pm \theta]_{n}$ Composite Laminate:}

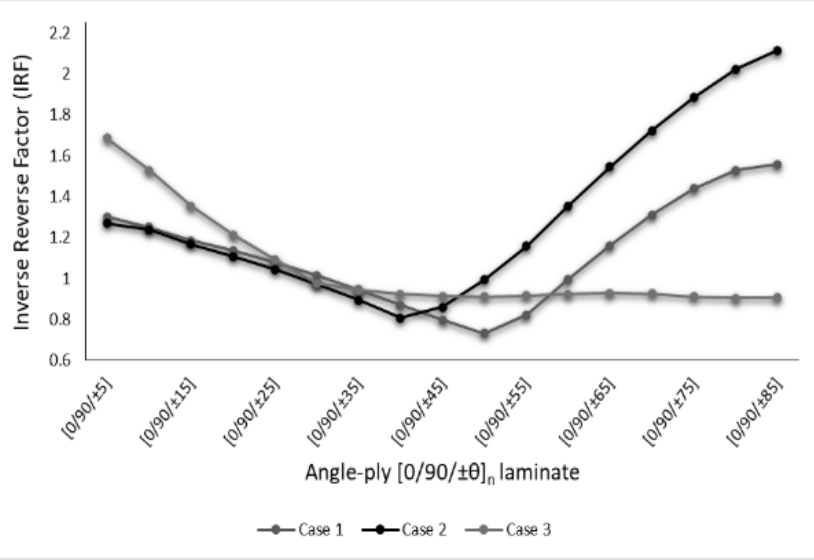

Figure 7 Graphical representation of Inverse Reverse Factors (IRF) for different angles in angle-ply [0/90/ $\pm \theta] \mathrm{n}$ laminate.

The number of layers (n) is set to 4, 7 and 2 for regions A, B and C respectively. At every interval of $5^{\circ}$, IRF was monitored for this laminate as well. It can be seen from the graph (see Figure 7), the optimum condition is achieved for $\left[0 / 90 / \pm 40^{\circ}\right] \mathrm{n}$ and $\left[0 / 90 / \pm 45^{\circ}\right] \mathrm{n}$ laminate. Further, the maximum stress values of these two laminates- $471.01 \mathrm{MPa}$ and $467.32 \mathrm{MPa}-\mathrm{were}$ compared and the laminate for which minimum stress value was obtained was selected. Similar to the previous laminate, the number of layers is varied and obtained results are listed in Table- IV. It is observed that 4, 7 and 2 layers at regions A, B and $\mathrm{C}$ respectively give the best output and hence they are finalised. The weight of the seat obtained in this case is $10.15 \mathrm{~kg}$.

Table- III: Effect of change in number of layers on output parameters of $[ \pm 45]$ n Angle-ply Laminate

\begin{tabular}{|c|c|c|c|c|c|c|c|c|c|c|c|c|c|}
\hline \multirow{3}{*}{ Laminate } & \multirow{2}{*}{\multicolumn{3}{|c|}{$\begin{array}{c}\text { No. of Layers } \\
\text { Region }\end{array}$}} & \multicolumn{3}{|c|}{ Case 1} & \multicolumn{3}{|c|}{ Case 2} & \multicolumn{3}{|c|}{ Case 3} & \multirow{3}{*}{ Weight } \\
\hline & & & & \multirow{2}{*}{ IRF } & \multirow{2}{*}{ Max. stress } & \multirow{2}{*}{$\begin{array}{c}\text { Max. } \\
\text { Def. }\end{array}$} & \multirow{2}{*}{ IRF } & \multirow{2}{*}{ Max. stress } & \multirow{2}{*}{$\begin{array}{l}\text { Max. } \\
\text { Def. }\end{array}$} & \multirow{2}{*}{ IRF } & \multirow{2}{*}{ Max. stress } & \multirow{2}{*}{$\begin{array}{l}\text { Max. } \\
\text { Def. }\end{array}$} & \\
\hline & $\mathrm{A}$ & $\mathrm{B}$ & $\mathrm{C}$ & & & & & & & & & & \\
\hline$[ \pm 45]_{\mathrm{n}}$ & 14 & 8 & 2 & 0.8916 & 327.18 & 11.99 & 1.0997 & 312.26 & 10.51 & 0.9937 & 515.08 & 9.77 & 9.77 \\
\hline$[ \pm 45]_{\mathrm{n}}$ & 15 & 9 & 3 & 0.8013 & 292.44 & 9.97 & 0.9348 & 278.61 & 8.75 & 0.8241 & 451.04 & 10.94 & 10.94 \\
\hline$[ \pm 45]_{\mathrm{n}}$ & 16 & 10 & 4 & 0.7106 & 256.82 & 8.32 & 0.8250 & 244.62 & 7.29 & 0.7865 & 320.25 & 12.14 & 12.14 \\
\hline$[ \pm 45]_{\mathrm{n}}$ & 17 & 11 & 5 & 0.6697 & 243.26 & 7.23 & 0.7666 & 242.35 & 6.38 & 0.6457 & 345.31 & 13.28 & 13.28 \\
\hline
\end{tabular}

Table- IV: Effect of change in number of layers on output parameters of [0/90/ $\pm \theta]$ Angle-ply Laminate

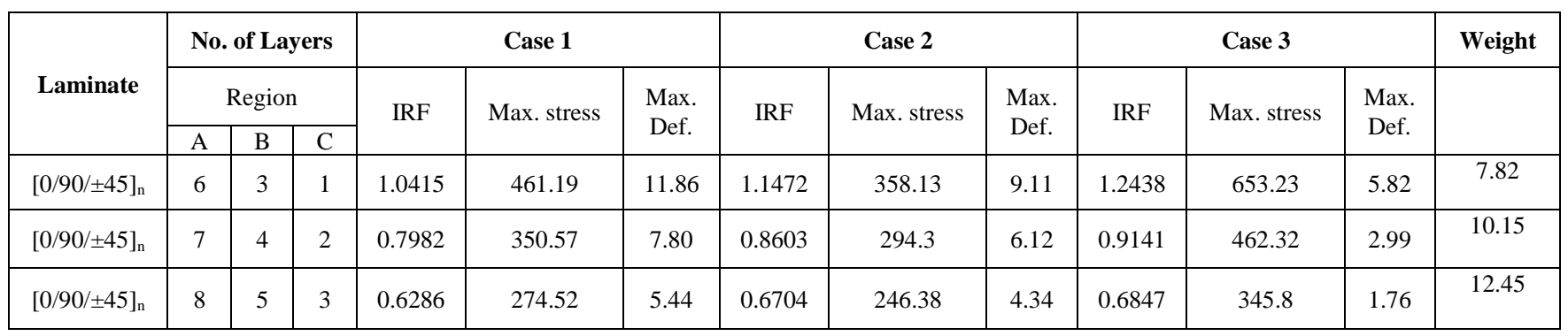

\section{CONCLUSION}

The weight optimization method of composite racing seat considering the lay-up sequence and orientation is described in this paper. Three types of lay-ups were considered to gain an optimum solution and the weight is calculated in each case. Studying different lay-up sequences and their orientation is an effective technique of optimizing composite laminate structures. The results obtained highlight the fact that the functioning of laminate depends on its strength as well as degree of anisotropy and stiffness. Angle-ply laminates with an angle of $45^{\circ}$ provide a more optimum design in comparison with cross-ply laminates. Comparing all the layup configurations it can be concluded that the angle-ply laminate with $[0 / 90 / \pm 45]_{n}$ configuration provides a minimum weight of $10.15 \mathrm{~kg}$ without hampering the required strength. 
Design Optimization of Composite Lay-up Sequence and Orientation to Achieve Minimum Weight for Racing Seat

APPENDIX

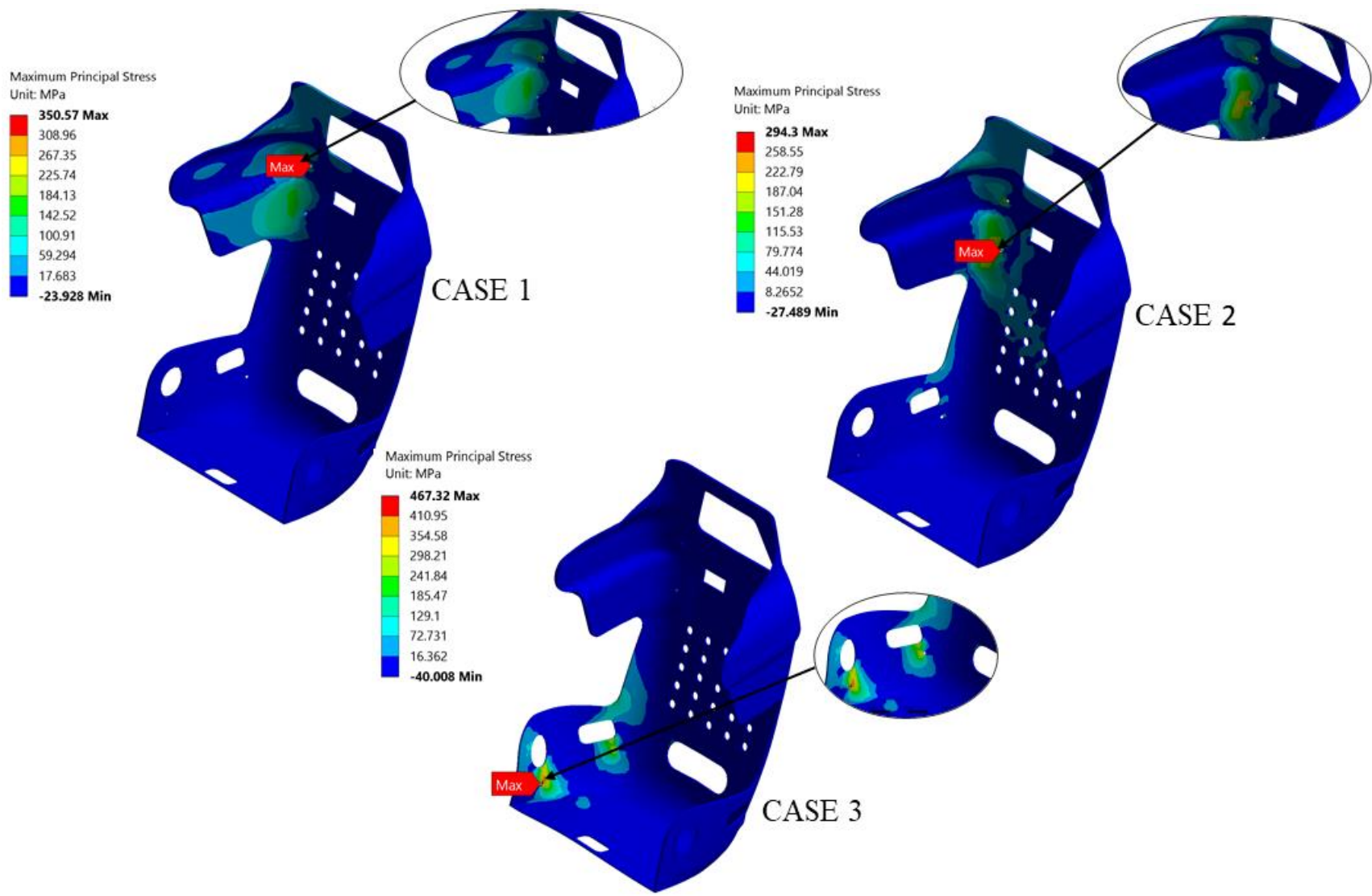

Figure 8 Stress contours for final cross-ply [0/90 $]_{n}$ composite laminate.

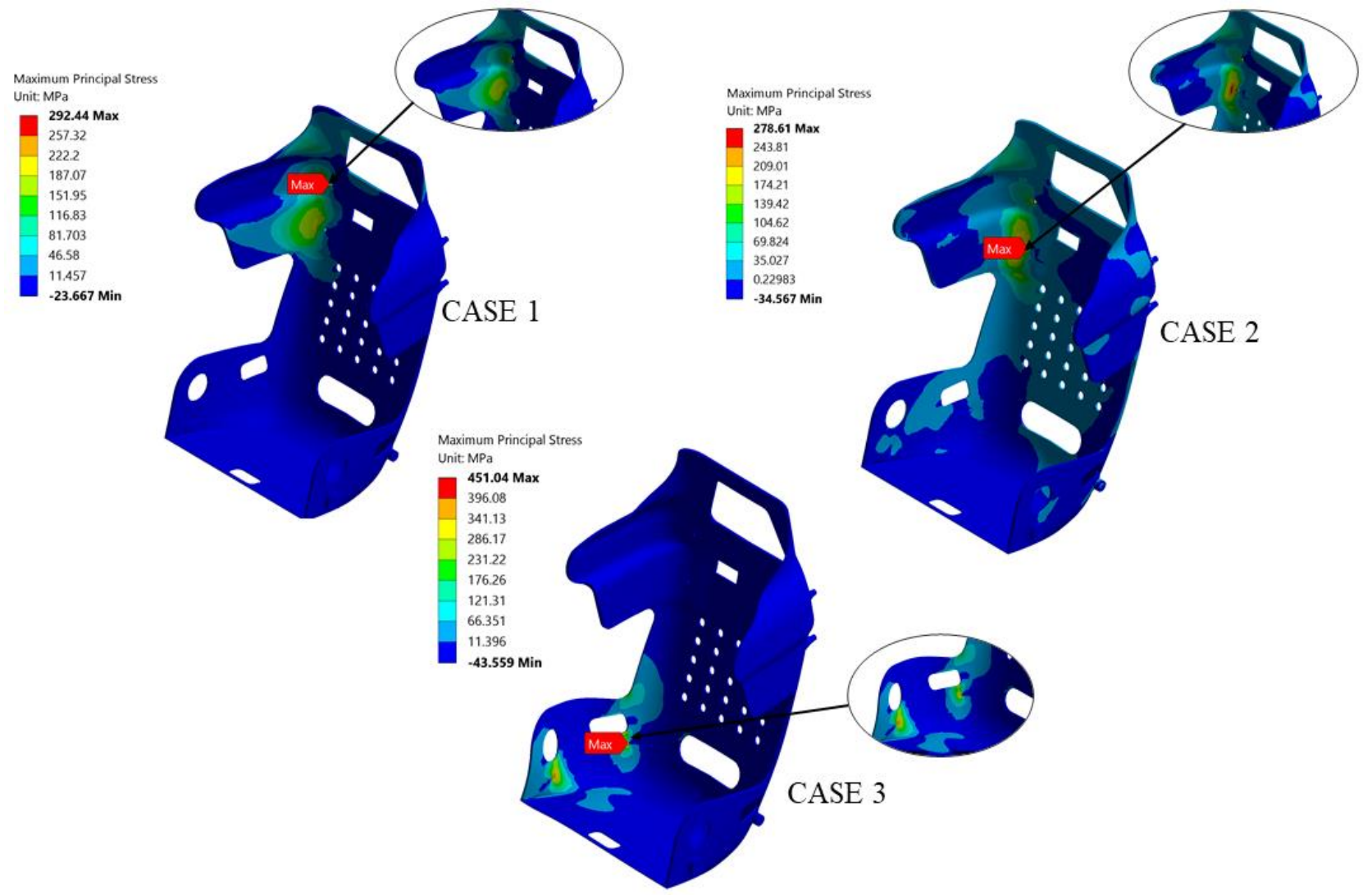

Figure 9 Stress contours for final Angle-ply $[ \pm 45]_{n}$ composite laminate.

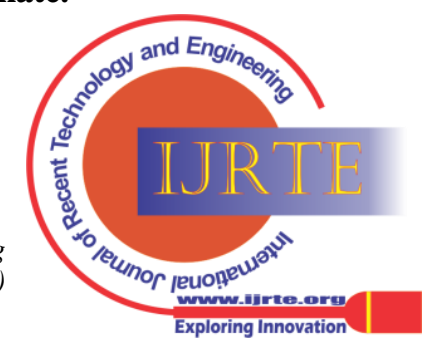




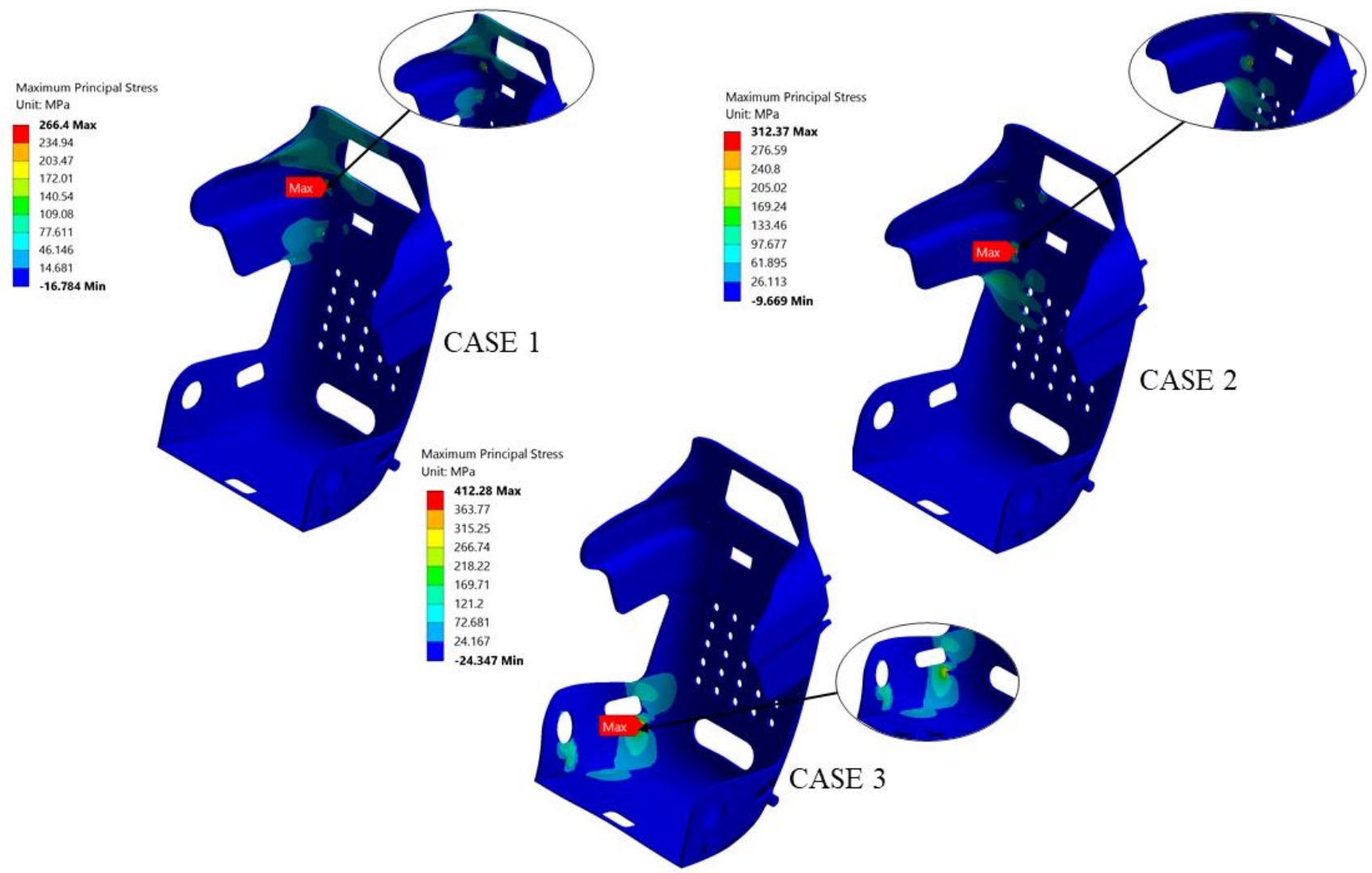

Figure 10 Stress contours for final Angle-ply $[0 / 90 / \pm 45]_{n}$ composite laminate.

\section{REFERENCES}

1. G. Savage, "Formula 1 Composites Engineering," Engineering Failure Analysis, vol. 17, no. 1, 2010, pp. 92-115, doi:10.1016/j.engfailanal.2009.04.014.

2. S. Shrivastava, H. Tilala, P. M. Mohite, and M. D. Limaye, "Weight by ply-drop," Structural and Multidisciplinary Optimization, vol. 17, no. 1, 2020, pp. 92-115, doi:10.1007/s00158-020-02569-5.

3. J. P. Blasques, M. Stolpe, "Maximum stiffness and minimum weight optimization of laminated composite beams using continuous fiber angles," Structural and Multidisciplinary Optimization, vol. 43, no. 4, 2010, pp. 573-588, doi:10.1007/s00158-010-0592-9

4. H. H. Mian, G. Wang, U. A. Dar, and W. Zhang, "Optimization of Composite Material System and Lay-up to Achieve Minimum Weight Pressure Vessel,” Applied Composite Materials, vol. 20, no. 5, 2013, pp. 873-889, doi:10.1007/s10443-012-9305-4

5. D. Liu, V. V. Toropov, D. C. Barton, and O. M. Querin, "Weight and mechanical performance optimization of blended composite wing panels using lamination parameters," Structural and Multidisciplinary Optimization, vol. 52, no. 3, 2015, pp. 549-562, doi:10.1007/s00158-015-1244-X

6. M. Chandak, H. Antariksh, C. Saurabh, and K. Chidambaram, "Numerical Study of Effect of Material and Orientation on Strength of Side Door Intrusion Beam," SAE Technical Paper 2019-28-0039, 2019, doi:10.4271/2019-28-0039

7. A. Sathaye, and I. Bhattacharyya, "Lightweighting of Automobile Hood Using Multistep Optimization for Composite Material," SAE Int. J. Adv. \& Curr. Prac. in Mobility, vol. 1, no. 1, 2019, pp. 113-119, doi:10.4271/2019-26-0168

8. R. Smith, S. Hayashi, Y. Kitagawa, and T. Yasuki, "A Study of Driver Injury Mechanism in High Speed Lateral Impacts of Stock Car Auto Racing Using a Human Body FE Model," SAE Technical Paper 2011-01-1104, 2011, doi:10.4271/2011-01-1104

9. J. Melvin, and T. Gideon, "Biomechanical Principles of Racecar Seat Design for Side Impact Protection," SAE Technical Paper 2004-01-3515, 2004, doi:10.4271/2004-01-3515

10. SFI Foundation., "SFI Specification 39.2," 2017, Available from: https://www.sfifoundation.com/wp-content/pdfs/specs/Spec 39.20825 17.pdf.

11. K. Y. Maalawi, "Use of material grading for enhanced buckling design of thin-walled composite rings/long cylinders under external pressure," optimization of a composite wing-panel with flutter stability constraints

Composite Structures, vol. 93, no. 2, 2011, pp. 351-359, doi:10.1016/j.compstruct.2010.09.007

12. J. Y. Zheng, and P. F. Liu, "Elasto-plastic stress analysis and burs strength evaluation of Al-carbon fiber/epoxy composite cylindrical laminates," Computational Materials Science, vol. 42, no. 3, 2008, pp 453-461, doi:10.1016/j.commatsci.2007.09.011

13. C. Kassapoglou, "Review of Classical Laminated Plate Theory," John Wiley \& Sons, pp. 33-53, doi: 10.1002/9781118536933

14. A. Kaw, "Mechanics of Composite Materials (2nd ed.)," CRC Press., doi:10.1201/9781420058291.

15. A. Puck, and H. Schürmann, "Failure analysis of FRP laminates by means of physically based phenomenological models," Failure Criteria in Fibre-Reinforced-Polymer Composites, 2004, pp. 264-297, doi:10.1016/b978-008044475-8/50011-1

16. G. Lutz, V. K. U. Getriebebau, "The Puck theory of failure in laminates in the context of the new guideline VDI 2014 Part 3," Conference on damage in composite materials, September, 2006.

17. R. Koh, and B. Madsen, "Strength failure criteria analysis for a flax fibre reinforced composite," Mechanics of Materials, vol. 124, 2018, pp. 26-32, doi: 10.1016/j.mechmat.2018.05.005

18. SAE Foundation, "The 2020 Formula SAE Rules," December 8, 2019, Available

from: https://www.fsaeonline.com/cdsweb/app/NewsItem.aspx?NewsItemID =2c1ab552-40c3-4b97-a258-582dca0ea505.

\section{AUTHORS PROFILE}

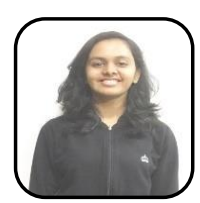

Ms. Pranali Yogesh Kajale, I have completed my undergraduate mechanical engineering in year 2021 from Sinhgad College of Engineering (SCoE), Pune which is affiliated to Savitribai Phule Pune University. have received several awards for my academic endeavors including the medal of academic excellence for securing 1st position in my department. My interest in field of automotive engineering has developed when I participated in a solar-electric vehicle manufacturing team. Along with being a part of team, I received an opportunity of leading the team for two years. My domains of interes include Vehicle dynamics, Structural Analysis, Computational Material Science, Product Design, manufacturing techniques. 